\title{
GRUPOS ONLINE: POSSIBILIDADES DE INTERVENÇÕES EM PSICOLOGIA NO CONTEXTO UNIVERSITÁRIO
}

\section{Liliane Tomazi Vestena'; Luciana de Andrade Silveira²; Márcia Elisa Jager ${ }^{3}$}

\section{RESUMO}

A prática grupal compreende uma das inúmeras possibilidades de intervenções realizadas pelo profissional psicólogo. Diante disso, alguns desafios foram impostos à prática psicológica a partir do contexto pandêmico na demanda para realização de grupos online. Neste trabalho, objetiva-se apresentar um relato de experiência sobre a prática de Estágio Básico II na realização de grupos online com estudantes universitários do curso de Nutrição da Universidade Franciscana para debater assuntos relacionados à vida acadêmica em tempos pandêmicos, além de outras demandas que emergiram no decorrer dos encontros grupais. Logo, observou-se que quanto à troca de experiências entre os indivíduos, inúmeras estratégias e intervenções são formadas, a fim de solucionar demandas emergentes do coletivo. A partir da prática realizada, conclui-se que presença de grupos em uma universidade é essencial para que se possa ouvir quais as dificuldades comuns ao âmbito acadêmico, visto que na maioria das vezes não há um espaço de escuta do no que se refere à forma como o (a) acadêmico (a) vivência o contexto universitário. Palavras-chave: Experiências; Pandemia; Prática grupal;

Eixo Temático: Atenção Integral e Promoção à Saúde (AIPS)

\section{INTRODUÇÃO}

Este trabalho tem como objetivo relatar a experiência da prática de Estágio Básico II em Psicologia, realizada com acadêmicos (as) matriculados (as) no curso

\footnotetext{
${ }^{1}$ Acadêmica do Curso de Psicologia. Universidade Franciscana -UFN. Email:liliane.tomazi@ufn.edu.br ${ }^{2}$ Acadêmica do Curso de Psicologia. Universidade Franciscana -UFN. Email: luciana.silveira@ufn.edu.br

30rientadora - Universidade Franciscana - UFN. Email: marcia.jaeger@ufn.edu.br
} 
de Nutrição da UFN, vinculado às ações do Programa de Atenção Integrada em Psicologia (PAIP) da Universidade Franciscana (UFN). A prática de estágio descrita tem como objetivo geral realizar o levantamento e pré-análise de demanda, delimitar o foco e enquadre de intervenção, compreender teórica e psicossocialmente a proposta, realizar atividades de observação e mediação de grupo bem como desenvolver o registro das ações em diário de bordo para discussões em encontros de supervisão.

A prática do psicólogo está para além daquela construída e reconhecida socialmente, baseada no modelo biomédico voltada para a intervenção do sofrimento psíquico e transtornos mentais no contexto da clínica privada. Logo, diante das demandas que a sociedade impõe que contemplam o coletivo inscrito em demandas sociais e culturais, o psicólogo adentra para campos mais amplos tendo um compromisso social por meio de práticas grupais. No entanto, existe um grande receio de muitos psicólogos (as) em trabalhar com práticas grupais devido a falta de conhecimentos teóricos e práticos suficientes e adequados sobre as técnicas utilizadas e o manejo grupal frente às demandas coletivas (RASERA; ROCHA, 2010). Isso revela a importância de se desenvolver conhecimentos, habilidades e atitudes no que se refere à intervenção em grupos no processo de formação acadêmica e profissional em Psicologia.

O reconhecimento de demandas coletivas e do indivíduo como um ser social que, desde o seu nascimento, pertence a diferentes grupos, colocam as práticas grupais como um conjunto de ferramentas imprescindíveis para as intervenções realizadas pelo profissional psicólogo. Ao vivenciar experiências grupais, o psicólogo tem a possibilidade de refletir sobre as suas vivências de grupo, além dos fenômenos e obstáculos que podem vir a surgir nesse processo (COSTA; SILVA; SILVEIRA, 2018).

No cenário atual, marcado pela pandemia da COVID-19, surgiram diversos desafios para a prática psicológica, entre elas destaca-se a realização de grupos pelo psicólogo no formato online. Embora se reconheça que essa forma de realizar 
encontros grupais proporcionam benefícios para os sujeitos, sabe-se que essa modalidade oferece também algumas limitações corporais e tecnológicas, relacionadas à acessibilidade, que podem prejudicar o bom andamento do processo grupal. Realizar intervenções grupais de forma online implica em construir uma ação baseada em métodos já utilizados na presencialidade, mas que carregam intervenção reinventadas, seguindo as normativas dos órgãos competentes de cada classe profissional (DONNAMARIA; TERZIS, 2011). Assim, parece relevante apresentar a prática de estágio realizada uma vez que a intervenção grupal assumiu características próprias e singulares que representam a experiência formativa em Psicologia no contexto da pandemia.

\section{METODOLOGIA}

Este trabalho é um relato de experiência de um grupo de treinamento / orientação formado a partir da iniciativa das acadêmicas de Psicologia e da professora supervisora. As práticas realizadas utilizaram como referência a abordagem cognitivo-comportamental em grupo. O grupo foi desenvolvido com os (as)acadêmicos (as) matriculados (as) em uma das disciplinas , do curso de Nutrição da UFN. O grupo contou com cinco participantes, se deu ao longo do primeiro semestre letivo de 2021, totalizando 6 encontros de 1 hora cada. Os encontros grupais ocorreram no formato remoto, na modalidade síncrona, pela plataforma Google Meet.

\section{RESULTADOS E DISCUSSÕES}

\subsection{PRÁTICA GRUPAL E SUAS INTERVENÇÕES}

Inicialmente, a proposta para a formação do grupo foi trabalhar os sentimentos e experiências provocadas pela pandemia da COVID-19 na rotina dos(as) acadêmicos(as) e na aprendizagem remota. No entanto, os objetivos dos encontros foram construídos a partir de uma demanda grupal.

O grupo configura-se como um conjunto de pessoas que possuem interesses 
em comum, ou seja, uma totalidade com suas próprias regras, sendo que todos os sujeitos trabalham em prol de uma tarefa e de um objetivo específico. No grupo ocorre uma interação entre os participantes que, embora formem uma identidade grupal, não deixam de demonstrar as suas próprias identidades. No desenvolvimento da intervenção em grupos é importante que se estabeleça a modalidade grupal para que o planejamento das ações ocorra de forma coerente. A escolha por uma modalidade grupal depende da finalidade e perspectiva teórica adotada. Na realização do estágio descrito, a modalidade grupal escolhida foi a de treinamento e/ou orientação (NEUFELD et al., 2017).

A modalidade de treinamento e/ou orientação busca guiar e trabalhar com os participantes nas demandas ligadas diretamente aos aspectos comportamentais, cognitivos, intelectuais e afetivos presentes em experiências de vida ou temas específicos que caracterizam interesse coletivo. Os encontros buscam construir um espaço no qual o indivíduo externe seus pensamentos, emoções e comportamentos e elabore suas dificuldades, conseguindo finalmente chegar ao êxito de conseguir mudanças em sua vida e em seu cotidiano (NEUFELD et al., 2017).

Compreende-se que o grupo de orientação e/ou orientação busca, através de técnicas cognitivas e comportamentais aplicadas ao coletivo, conduzir e instruir os integrantes do grupo a alcançar transformações em áreas fundamentais na saúde do sujeito. Assim, esta modalidade apropria-se aos estágios direcionados a grupos, ou seja, aqueles que tem como objetivo provocar modificações cognitivas, intelectuais, afetivas e de conduta.

No primeiro encontro realizado, trabalhou-se com o grupo as expectativas em relação aos encontros grupais, além da identificação dos sentimentos causados pela pandemia no que se refere ao contexto universitário a partir de uma dinâmica de "quebra-gelo". Além disso, realizou-se o contrato com as participantes e demais documentos exigidos pela instituição para que a prática do estágio pudesse ocorrer. Os sentimentos trazidos em relação à experiência universitária no contexto pandêmico foram ansiedade, medo e insegurança em relação ao futuro. Esta 
realidade é comum, conforme sugere Vieira et. al (2020).

Vieira et al. (2020) destacam que, diante da pandemia da COVID-19 o isolamento social para a contenção do vírus foi a principal estratégia de controle da doença. As instituições educativas tiveram que adaptar as atividades no formato remoto / síncrono / assíncrono. Desse modo, os (as) estudantes tiveram que lidar com o ensino nesse novo formato, contribuindo para intensas mudanças e desafios no estado emocional dos mesmos. Os autores destacam que, mesmo sabendo da importância do isolamento social, é comum no contexto educacional a emergência de sentimentos como ansiedade, estresse e angústia que interferem de modo direto na satisfação de vida das pessoas e no processo de aprendizagem.

No segundo encontro, utilizou-se uma técnica da Terapia Cognitiva conceituada como Registro de Pensamento Disfuncionais (RPD) para trabalhar a expressão dos sentimentos e emoções. Esta técnica possibilita identificar os pensamentos automáticos para poder avaliá-los frente às suas evidências e modificá-los (BECK, 2013). Assim, foi proposto que as participantes descrevessem uma situação ligada à experiência universitária no contexto da pandemia que se sentiram emocionalmente desconfortáveis, depois identificassem os pensamentos, as emoções e os comportamentos associados. As situações apresentadas no grupo foram: estudar a distância, excesso de tempo na frente das telas e falta de concentração para aprender. Em relação aos pensamentos apresentados, os (as) participantes relataram a incerteza de quando essa situação vai passar, insegurança, falta de esperança e expectativas reais de retorno. As emoções e sentimentos apresentados foram os associados à ansiedade e medo do futuro.

Convém lembrar que a pandemia da COVID-19 provocou inúmeras mudanças na vida das pessoas, de forma geral. Por isso, recomenda-se que haja sempre que possível uma atenção e escuta maior para relatos do ser humano, pois a pandemia provocou e, infelizmente ainda acarreta, muitas incertezas, angústias e sofrimentos psíquicos no indivíduo (MORETTI; GUEDES-NETA; BATISTA, 2020). Ao se examinarem alguns aspectos relacionados à saúde dos jovens, verifica-se que ao 
passar muitas horas em frente ao computador ou simplesmente sem praticar nenhum tipo de atividade física, pode causar diversos danos à sua saúde (TAMMELIN, 2009). Neste sentido, reconhecer os pensamentos, emoções e comportamentos associados às experiências ligadas à pandemia pode proporcionar um maior controle sobre os desconfortos emocionais gerados.

No terceiro encontro, refletiu-se a respeito dos padrões de beleza impostos pela sociedade e como eles influenciam na saúde mental da população, bem como a influência das mídias no desenvolvimento de transtornos. Esta demanda emergiu do próprio grupo, no segundo encontro, a partir de pensamentos ansiosos ligados ao corpo e beleza gerados pelas mídias sociais e a maior exposição à elas no período da pandemia. Como dispositivo utilizou-se trechos dos vídeos: "Bulimia - curta metragem" e "Doll Face - curta sobre a ditadura da beleza". Ao longo das discussões percebeu-se que os (as) participantes buscavam estratégias para enfrentar os padrões já enraizados, tal como ficar um tempo afastada das redes sociais, ler textos, entre outros mecanismos de defesa. Além de descreverem o quanto se sentem desconfortáveis em relação à constante demanda que emerge dos fatores relacionados à cobrança do corpo padrão por estarem em um curso de nutrição. A sociedade em que vivemos impõe diversos estereótipos enraizados que são perpassados, principalmente pelas mídias sociais e indústrias de beleza. Esses corpos "perfeitos" que são disseminados nas revistas, novelas, comerciais, muitas vezes, tornam-se uma cobrança para as pessoas, sendo que não atingi-lo causa intenso sofrimento e afeta a saúde mental (BARBOSA; SILVA, 2016). Como demanda no grupo surgiu a necessidade de discutir sobre como construir estratégias adequadas no enfrentamento da ansiedade, especialmente quando ela é causada por pensamentos distorcidos ligados ao corpo e aos padrões de beleza.

No quarto encontro, trabalhou-se a relação entre ansiedade e o comportamento alimentar, além da importância do trabalho em conjunto entre a Psicologia e a Nutrição na modificação desses comportamentos e dos pensamentos e emoções associados a eles. Utilizou de questões a partir do dispositivo Kahoot 
para impulsionar a discussão grupal e o foco foi a psicoeducação de como as emoções interferem diretamente nos pensamentos ansiosos e na manutenção da ansiedade. A partir disso, foi pensado coletivamente algumas estratégias cognitivas e comportamentais para trabalhar com essa ansiedade. É notável o quanto a ansiedade pode acarretar em muitas consequências, tanto positivas quanto negativas, na rotina. A ansiedade pode ser caracterizada pelo surgimento de diversos aspectos, lembrando sempre que cada ser humano irá lidar de uma forma diferente frente a ocorrências semelhantes (MARGIS, et al; 2003 ). A demanda grupal revelou a necessidade de continuar conversando sobre o tema.

No quinto encontro, o objetivo foi atingido por meio de duas questões no Mentimeter. Buscou-se trabalhar quais os pensamentos que surgem diante da ansiedade e quais as estratégias para lidar com esses pensamentos. A partir da discussão das experiências trazidas pelas participantes, trabalhou-se a estratégia para a mudança do comportamento frente à ansiedade. Essa refere-se a identificar os pensamentos que estão causando ansiedade, questioná-los e relativizá-los para que não se tornem verdades absolutas. Além disso, identificar as distorções cognitivas presentes e verificar os níveis de evidências de que esses pensamentos venham a se concretizar ou não. Distorções cognitivas são pensamentos considerados como verdade absoluta pelos indivíduos, e que devem ser analisados quanto a sua veracidade a partir das evidências ambientais. Em função desses pensamentos conterem em algum grau alguma verdade, há uma tendência de encontrar alguma evidência que comprove que essa distorção é verdadeira. Por isso, a reflexão e capacidade de questionar são as principais habilidades cognitivas a serem desenvolvidas (BECK, 2013).

Ademais, é preciso ter cuidado com algumas distorções cognitivas que possam vir a surgir, como também em verificar que evidências temos de que essas venham a se concretizar de fato ou não. Isso parte do pressuposto básico da Terapia Cognitiva que defende que o que causa o sofrimento não é a situação em si, mas a 
forma como a interpretamos e, por isso, mudar os pensamentos gera mudanças emocionais e comportamentais (BECK, 2013).

O sexto encontro foi direcionado para o feedback final no qual foi compartilhada a experiência na realização do grupo e da própria experiência do estágio curricular em Psicologia. Também realizou-se uma devolução reforçando o esforço que (os) as participantes do grupo fizeram para estarem conectadas ao longo do desenvolvimento do grupo em meio a outras tantas demandas semestrais. Como devolução dos encontros grupais, (os) as participantes trouxeram que tinham considerado os momentos de encontro um espaço proveitoso para o compartilhamento das suas experiências acadêmicas e outras que emergiram a partir das discussões realizadas.

\section{CONCLUSÃO}

A prática grupal possibilitou o desenvolvimento de habilidades de manejo em grupos, além do planejamento de intervenções que pudessem auxiliar na discussão das demandas coletivas identificadas. Além disso, foram desenvolvidas estratégias interventivas a partir da demanda que surgia em cada encontro com a finalidade de troca de experiências, evidenciando a dinamicidade e complexidade que envolve a intervenção grupal. As práticas agregaram imensamente para a formação acadêmica em Psicologia, pois planejar e atuar na intervenção um grupo certamente é essencial para que, futuramente, caso necessário, saiba-se coordenar um grupo. .

Dentre os desafios encontrados na realização da prática grupal, destaca-se a dificuldade na adaptação das dinâmicas para o formato online, pois a maioria delas inicialmente foram pensadas para serem aplicadas de forma presencial. Além disso, a participação assídua dos (as) integrantes do grupo, pois como a prática estava sendo realizada no formato online, em algumas vezes, devido ao cansaço e a excessiva exposição a tela do computador, os (as) participantes acabaram não comparecendo ao dia e horário marcados. 


\section{REFERÊNCIAS}

BECK, J. S. Terapia cognitivo-comportamental: teoria e prática /Judith S. Beck; tradução: Sandra Mallmann da Rosa; revisão técnica: Paulo Knapp, Elisabeth Meyer. - 2. ed. - Dados eletrônicos - Porto Alegre: Artmed, 2013.

BARBOSA, B. R. S. N.; SILVA, L. V. da. A mídia como instrumento modelador de corpos: um estudo sobre gênero, padrões de beleza e hábitos alimentares. Razón y Palabra, vol. 20, n. 94, p. 672-687, 2016. Disponível em: https://www.redalyc.org/pdf/1995/199547464041.pdf. Acesso em: 04 Maio 2021.

COSTA, J. T.; SILVA, F. S. da; SILVEIRA, C. A. B. As práticas grupais e a atuação do psicólogo: intervenções em grupo no estágio de processos grupais. VINCULO Revista do NESME, v. 15, 2018. Disponível em: http://pepsic.bvsalud.org/scielo.php?script=sci_abstract\&pid=S1806-2490201800020 0005\&lng=es\&nrm=iso\&tlng=pt. Acesso em: 29 de Mar. de 2021.

DONNAMARIA, C. P.; TERZIS, A. Experimentando o dispositivo terapêutico de grupos via internet: primeiras considerações de manejo e desafios éticos. Revista da SPAGESP - Sociedade de Psicoterapias Analíticas Grupais do Estado de São Paulo, v. 12, n. 2, p. 17 - 26, 2011. Disponível em: http://pepsic.bvsalud.org/pdf/rspagesp/v12n2/v12n2a03.pdf. Acesso em: 29 de Mar. de 2021.

MARGIS, R. et al. Relação entre estressores, estresse e ansiedade. Rev. psquiatr. RS. Porto Alegre, v. 25, n. 1, p. 65-74, abril. 2003. Disponível em: https://www.scielo.br/pdf/rprs/v25s1/a08v25s1.pdf. Acesso em: 19 de Mai. de 2021. 
MORETTI, S. A.; GUEDES-NETA, M.L.; BATISTA, E. C. Nossas Vidas em Meio à Pandemia da COVID - 19: Incertezas e Medos Sociais. Rev Enfermagem e Saúde Coletiva, Faculdade. São Paulo, v. 4, n. 2, p.32-41. 2020. Disponível em: https://www.researchgate.net/profile/Sarah-Moretti/publication/342898913_Nossas_V idas_em_Meio_a_Pandemia_da_COVID_-19_Incertezas_e_Medos_Sociais_Our_Liv es_in_The_Midst_of_The_COVID_Pandemic_-19_Social_Uncertainties_and_Fear/li nks/5f0c80b892851c38a519c2c0/Nossas-Vidas-em-Meio-a-Pandemia-da-COVID-19Incertezas-e-Medos-Sociais-Our-Lives-in-The-Midst-of-The-COVID-Pandemic-19-So cial-Uncertainties-and-Fear.pdf. Acesso em: 20 de Abr. de 2021.

NEUFELD, C.B.; MALTONI, J.; IVATIUK, A.L.; RANGÉ, B.P. Aspectos técnicos e o processo em TCCG. IN NEUFELD, C.B., \& RANGÉ, B.P. (Orgs.). Terapia Cognitivo-Comportamental em Grupos: das evidências à prática. Porto Alegre: Artmed., p. 33-54, 2017.

RASERA, E. F.; ROCHA, R. M. G. Sentidos sobre a prática grupal no contexto de saúde pública. Psicologia em Estudo, Maringá, v. 15, n. 1, p. 35-44, 2010. Disponível em:https://www.scielo.br/scielo.php?pid=S1413-73722010000100005\&script=sci_abs tract\&tlng=pt. Acesso em: 29 de Mar. de 2021.

TAMMELIN, T. Falta de atividade física e excesso de tempo sentado: perigos para a saúde dos jovens?. Jornal de Pediatria. Porto Alegre, v. 85, n. 4. 2009. Disponível em:https://www.scielo.br/scielo.php?pid=S0021-75572009000400002\&script=sci_artt ext\&tIng=pt. Acesso em: 27 de Abr. de 2021.

VIEIRA, K. M. et al. Vida de estudante durante a pandemia: isolamento social, ensino remoto e satisfação com a vida. EaD em Foco, v. 10, n. 3, 2020. Disponível em: $\quad$ https://eademfoco.cecierj.edu.br/index.php/Revista/article/view/1147/574. Acesso em: 20 abr. 2021 